\title{
"TRAGÉDIAS BRASILEIRAS": O DIÁLOGO DE DALTON TREVISAN COM MANUEL BANDEIRA E NELSON RODRIGUES
}

\author{
Cleusa Rios Pinheiro Passos *
}

RESUMO: O conto "O senhor meu marido" de Dalton Trevisan recupera intertextualmente elementos provenientes de um poema de Manuel Bandeira ("Tragédia Brasileira”) e de uma peça de Nelson Rodrigues (Dorotéia). Trata-se de uma rede dialógica que diz respeito a temas relativos a desejo, censura e "sujeição feminina" e exercita, por outro lado, a intertextualidade no interior da literatura brasileira, vista como um campo de possibilidades a serem exploradas .

PALAVRAS-CHAVE: intertextualidade; Dalton Trevisan; literatura brasileira.

1 primeira vista, passam despercebidas ao leitor de "O senhor as presenças de "Tragédia Brasileira" de Bandeira ${ }^{2}$ e Dorotéia ${ }^{3}$ de Nelson Rodrigues como textos-elos de uma rede dialógica a conferir persistência e tom peculiares aos temas do desejo, censura e "sujeição feminina". Elaborados por formas distintas e oriundos de contextos diversos, insistem e contribuem para a ciranda inventiva que, pouco a pouco, ultrapassa a costumeira "repetição" de Dalton, sugerindo traços mnêmicos, reveladores de nossa "tradição".

As relações com obras estrangeiras, desde sempre atuantes na literatura brasileira, vão se solidificando por meio do cruzamento de autores

* Departamento de Teoria Literária e Literatura Comparada - FFLCH/USP.

1 Republicado na obra do autor Em busca de Curitiba Perdida. Rio de Janeiro: Record, 1992, p. 37 -40.

2 Cf. BANDEIRA, M. "Estrela da Manhã". Em seu Poesia Completa e Prosa. Rio de Janeiro: José Aguilar, 1967, p. 283.

3 Em seu Teatro quase completo. Volume II. Rio de Janeiro: Tempo Brasileiro, 1965, p. 16-107. 
PASSOS, Cleusa Rios Pinheiro. "Tragédias brasileiras": o diálogo de Dalton Trevisan...

agora também pertencentes aos quadros nacionais, marcando uma espécie de tensão em que estes últimos e o influxo de criações e movimentos além-fronteiras se integram de modo sutil, a ponto de o leitor não desconfiar da conexão intersemiótica, estabelecida por uma narrativa pouco estudada pela crítica, de tom reduzido, mas, curiosamente, espaço de ressonâncias poéticas e teatrais.

Dentre as preocupações de Dalton Trevisan, duas dizem respeito à questão que nos concerne: a forte ligação com a terra natal, responsável por uma "viagem" ao universo de Curitiba e um metafórico "vampirismo". Essa circularidade manifesta-se, em grande parte, na maneira de reconstituir fatos pretéritos, base de sua história pessoal e literária, remetendo à segunda característica mencionada: a apropriação da matéria alheia $^{4}$, no aparente retorno ao ponto de partida.

Uma de suas reiteradas características implica revisitar o mundo curitibano, sublinhando costumes e personagens sem grandeza, recobrando cenas contíguas, insinuadoras de certo encadeamento de situações específicas, em diferentes livros. Além disso, a fragilidade dos vínculos existenciais no contexto urbano e, basicamente, pequeno-burguês se faz um dos principais índices do conjunto de seus escritos, ao lado da procura de trajetória dialógica que sugere, por exemplo, as presenças de Cervantes e Proust, nos títulos de Novelas nada exemplares ou Em busca de Curitiba Perdida.

"Pretensão sem surpresa", no dizer de Otto Maria Carpeaux ${ }^{5}$, ou lucidez diante das reinvenções paródicas de textos pessoais e alheios? Não descartando inteiramente a perspicácia do crítico, é preciso relativizá-la em alguns momentos, sobretudo quando se conformam cadeias dialógicas, transfiguradoras das leituras de Dalton, em recomposições nas quais im-

\footnotetext{
+ Algumas relações sobre o diálogo entre Dalton e Bandeira, agora desenvolvidas, surgiram quando de uma resenha feita sobre seu livro Em busca de Curitiba Perdida, op. cit., para a Revista USP, São Paulo, 1994, 22, p. 21-28.

5 V. CARPEAUX, O. M. Livros na Mesa. Rio de Janeiro: Liv. São José, 1960, p. 250-5.
} 
Rev. ANP()LL, n. 6/7, p. 21-35, jan./dez. 1999

prime feições particulares, recordando, paralelamente, obras importantes, tais como as de Bandeira e Nelson Rodrigues - interesse maior de nosso olhar.

$\Lambda$ ambivalência estética dos dados repetitivos no trabalho do escritor ganha função nas passagens em que, ao reescrever e reordenar o ficcional, evoca a memória literária e o instrumento para a apropriação do outro se ancora no ato de recriar com vistas à redimensão das "fontes" escolhidas. Desde $O$ vampiro de Curitiba, a crítica ${ }^{6}$ não tem obliterado o apequenamento da figura do Vampiro que, de aristocrata torna-se personagem sem singularidade, integrando-se à metáfora da sucção vampiresca, cujo intuito básico é o processo de conversão do "outro" em sua própria imagem sugestivamente diminuta e rebaixada.

De maneira ampla, o autor "suga" textos de escritores nacionais ou estrangeiros (entre eles Gonçalves Dias, Vinícius de Moraes, García Lorca, Fernando Pessoa etc.) para construir o seu e utiliza, parcialmente, recurso comparado ao do vampiro, ou seja, aspectos de grandes obras também são redimensionados, porque se incorporam ao cotidiano, estreito e sem brilho da sua Curitiba. Com freqüência, os traços literários de Trevisan ocultam figuraçōes significativas e aí aflora o inesperado intercâmbio de renomados escritos.

Teoricamente, considera-se aqui a lição de Kristeva que, na esteira de Bakthin, cria o termo intertextualidade, consignando o texto como "espaço" de convergência, transformações e diálogos ${ }^{7}$. Nliás, é essa busca de "novos" elementos estéticos e culturais, apoiados na assimilação e mudança, que torna enriquecedores os pressupostos da autora, pois abrem possibilidades para leituras veiculadoras de sentidos além do texto em si, ou seja, ao recuperar lembranças de outros - deslocados de seu lugar de origem - alcança, em tais relações, diversidade inventiva.

6 Cf., entre outros, WALDMAN, B. Do vampiro ao cafajeste - uma leitura da obra de Dalton Trevisan. São Paulo/Curitiba: Hucitec/Sec. da Cultura e do Esporte do Governo do Est. do Paraná, 1982.

7 V.KRISTEVA, J. "A palavra, o diálogo e o romance”. Em seu Introduçāo à Semanálise. São Paulo: Perspectiva, 1974, (Col. Debates, 84), p. 61-90. 
PASSOS, Cleusa Rios Pinheiro. "Tragédias brasileiras": o diálogo de Dalton Trevisan...

Quanto à questão valorativa, as três construções aqui vinculadas não apresentam o mesmo grau, todavia, não se trata apenas de apontar "O senhor meu marido" como um elo a mais na cadeia constitutiva da história da literatura brasileira. $\mathrm{O}$ ficcionista curitibano ultrapassa a mera apropriação e, se não atinge o mesmo sucesso de seus antecessores, sem dúvida, escapa a uma "recepção passiva", propiciando ao conto a irreverência de seu tom e perspectiva, aliado ao discreto caráter centralizador ${ }^{8}$ para diálogos profícuos, instituídos a partir de um fino despertar da memória.

Assim, somente a familiaridade com Manuel Bandeira permite entrever o poema-prosa "Tragédia Brasileira" em "O senhor meu marido", revivendo-se mudanças de bairro, efetuadas pelo casal-protagonista, em virtude das traições da mulher, no intento de afastá-la de seus amantes. No fim do primeiro parágrafo, uma frase paralelística - "dava tudo o que ela pedia" - antecipa o fio dialógico a ser urdido, pois recobra a constatação "dava tudo quanto ela queria", fecho do primeiro momento do poema revisitado.

$\Lambda$ narrativa de Dalton não contém a forte mescla de prosa e lirismo, a um tempo, sugestiva da banalização e do universo poético fugaz de que participam "Misael e Maria Elvira". Suas personagens, os mesmos João e Maria de tantas narrativas, rarefazem o lírico, uma vez que se delineiam graças a pormenores triviais, reiterativos de um modo de compor específico.

Misael vira João, garçom do Buraco do Tatu, "manso" e devotado à infiel Maria. Os bairros pelos quais se deslocam reconstituem a decantada Curitiba e o produto das ligações afetivas são "novas Marias", filhas adulterinas, porém sempre resguardadas pelo infeliz marido. Disposto a receber a amada e "única" em passagens constrangedoras, ele preserva impressões de felicidade - misto de "morbidez" e engano, se pensarmos na

8 V. JENNY, L. "La stratégie de la forme". Poétique, Seuil, 27, 1976, p. 257-281. 
Rev. $A N P() L L$, n. 6/7, p. 21-35, jan./dez. 1999

incessante repetição que substitui o prazer pela dolorosa expectativa das traições futuras, virtuais desdobramentos do passado.

Logo, Dalton se apossa de aspectos de "Tragédia Brasileira" para elaborar uma tragédia - a curitibana - determinada por intensa minimização. Já a de Bandeira anunciava tal processo por meio de seres ficcionais delineados precariamente. Misael apresenta perfil restrito (63 anos de idade, "funcionário da Fazenda") e conhece Maria Elvira "na Lapa - prostituída, com sífilis, dermite nos dedos, uma aliança empenhada e os dentes em petição de miséria". $\Lambda$ configuração fragmentária da moça, delimitada pelo uso de metonímias, revela um corpo simbolicamente estilhaçado.

Da aliança (noivado ou casamento?) empenhada, alusiva a perdas afetivas e pobreza, à escolha do particípio ("prostituída") no lugar do substantivo (prostituta), a mulher surge como objeto amoroso ou desejante ${ }^{9} \mathrm{e}$ discursivo. É tirada "da vida" por quem, depois, lhe tirará "a vida"; é instalada num sobrado e "reconstruída" fisicamente por médico, dentista, manicura, às custas de Misael, sujeito social e pagante, conforme também será o garçom do "Buraco do Tatu".

No entanto, quando "se apanha" de boca bonita, Maria Elvira arranja um namorado, restabelecendo-se como sujeito no corpo textual e retornando à situação anterior; agora, preservada pela hipocrisia moral do ocultamento. O "anônimo" funcionário "podia dar uma surra, um tiro, uma facada", ou seja, encontra-se protegido por prerrogativas de um mundo masculino, representativo de posições tradicionais: ao homem cabe prover a casa e organizar as finanças (não por acaso, ele é funcionário da "Fazenda"), à mulher fidelidade e cuidados caseiros.

Mais prosaico, o marido João "corre amantes", tenta espancar e ameaçar com a "faca dentada de pão", mas cede ao "volume da barriga"

9 Tais termos são aqui, por analogia, empregados no sentido psicanalítico, estabelecendo-se, em linhas gerais, diferenças entre desejo - "metonímia da falta-a-ser" e de seu objeto perdido (sem visar, necessariamente, o objeto amado e sem relações com um "objeto real") - e demanda, ligada ao amor e dirigida a outrem. V. LACAN, J. entre outros, Le Séminaire, livre XI, Les écrits techniques de Freud. Paris: Seuil, p. $65-$ 181 e Le Séminaire VIII, Le transfert. Paris: Seuil, 1991, 29-195. 
PASSOS, Cleusa Rios Pinheiro. "Tragédias brasileiras": o diálogo de Dalton Trevisan...

da companheira, refazendo a trajetória de Misael: troca de casa e bairros humildes de Curitiba. Cabe pontuar que, em nome do escândalo a ser evitado, a personagem do poema efetuara roteiro análogo, transferindo-se pelos bairros pobres do Rio de Janeiro, cada vez que a parceira arranjava "namorado", outro termo encobridor do que não deveria vir à luz nos líricos versos de Bandeira.

Cabe, aqui, uma focalização mais minuciosa do processo de "Tragédia Brasileira", antes da retomada especular de seus pares curitibanos. De modo literal, "os amantes cariocas moraram no Estácio, Rocha, Catete, Rua General Pedra, Olaria, Ramos, Bom Sucesso, Vila Isabel, Encantado, Rua Clapp, outra vez no Estácio, Todos os Santos, Catumbi, Lavradio, Boca do Mato, Inválidos...", suspendendo-se a enumeração num ponto chave, o da fragilidade de Misael e do leitor - ambos já sem "vigor" para mudança de local ou seguimento da leitura, sistematizada numa corrente nominal contínua, só interrompida por inquietantes reticências.

$\Lambda$ falta de trégua, em função do desejo de Maria Elvira, desemboca na morte, caminho trilhado pelo funcionário que a mata "com seis tiros" "privado de sentidos e de inteligência" - na Rua da Constituição. Não custa lembrar que o logradouro abrigava anteriormente cidadãos marginalizados, considerados de "terceira classe", sem direitos e proibidos de exercer cargos públicos, registrando-se, ainda, historicamente como antiga "zona de meretrício" 10 .

Tal rastreamento se mostra expressivo pelas marcas da memória social, o assassinato e as associações possíveis da palavra "Constituição". Ironicamente, datado de 1933, o texto poderia reavivar a lembrança do clima da $\Lambda$ ssembléia Constituinte, para a qual se elege uma mulher, cujo direito ao voto se instituíra pouco antes: de um lado, voz institucional, de outro, o silêncio como punição pelo ato transgressor.

10 Cf. COARACY, V. Memórias da Cidade do Rio de Janeiro. Belo Horizonte: Itatiaia; São Paulo: Editora da Universidade de São Paulo, 1988, (Col. Reconquista do Brasil, 2. série; v. 132), p. 77-99. 
Ora, ao empregar tom e linguagem jornalísticos, informando que Maria Elvira fora achada pela polícia "caída em decúbito dorsal" e generalizando os dados sobre o objeto da notícia, o eu lírico, paralelamente, expõe e rompe a reificação do casal, finalizando com um traço singular e poético da mulher desejante e desejada: o vestido "de organdi azul" leveza e colorido confirmam sua posição de sujeito, contrapondo-se, sem o saber, ao universo que a cerca.

$\Lambda$ lei não impede os protagonistas de perseguirem cegamente seus desejos. $\Lambda$ miséria da mulher e a solidão do parceiro os levam a se unir; entretanto, desejos e demandas não coincidem! ${ }^{11}$. Por analogia, metáfora e metonímia revelam-se mecanismos básicos e diferenciais, pois também conferem ao texto a distância da mera notícia de jornal, configurando operações responsáveis pela forma poética, à primeira vista predominantemente prosaica.

Os nomes dos bairros substituem o dos amantes, recurso funcional para despistar a censura, consistindo em uma espécie de conteúdo manifesto a velar o latente - no fundo, o amante é sempre o "mesmo" representado por "vários" e a vertiginosa busca de espaço desconhecido mascara a ausência de mudança de postura interna. Contudo, a insistência que comporta a tensão entre o "outro" e o "mesmo" acaba engendrando a morte.

Situação parecida ocorre em "O senhor meu marido". O tom cotidiano e o lado "realista", contidos nas características iniciais dos seres de "Tragédia Brasileira", ganham intensidade na pena de Dalton, multiplicando-se em miudezas prosaicas, enfeixadas em parágrafos-cena, nos quais as variações de amantes (motorista, sargento, "malandro de bigode fino" etc.), deleites e flagrantes de infidelidade acabam redundando na tensão já determinante - do desenlace de Misael e Maria Elvira.

No conto, também a morte mostra outra faceta, surgindo, paradoxalmente, metafórica e banal, por meio do desgaste cotidiano provocado

11 Cf. nota 9. 
PASSOS, Cleusa Rios Pinheiro. "Tragédias brasileiras": o diálogo de Dalton Trevisan...

pelo retorno de situações idênticas e falta de saída. João não mata como o funcionário carioca, porém, deixado por Maria, vai encontrá-la, doente e abandonada, numa pensão de mulheres, tratando prontamente de curála. De maneira inversa - marca intertextual a ser registrada - reproduz-se o início da história de Misael, acrescido do elemento que cunha a narrativa, enquanto criação dialógica: no varal da nova moradia do garçom, tremula "cueca de monograma diferente", embaraçoso índice da contínua troca de amantes.

Os vínculos dialógicos não se esgotam com Bandeira, ampliando-se na discreta, mas vigorosa, presença de Nelson Rodrigues. O título do conto sugere a retomada de uma frase da peça Dorotéia, "farsa irresponsável", no dizer de seu autor - aqui enfocada pela construção discursiva e não por suas intrigantes encenações ${ }^{12}$, lacuna inerente à abordagem literária do teatral.

Bela, rosto nu e vestida de vermelho - análoga "às profissionais do amor, no príncipio do século" - Dorotéia procura as parentes, D. Flávia, Carmelita e Maura, três viúvas de luto, encobertas por longos e castos vestidos, leques e máscaras a ocultar-lhes "curvas" e faces. Jamais dormiram, a fim de evitar sonhos irrompedores de "volúpias secretas e abomináveis".

Condenadas a experimentar a "náusea" na primeira noite de núpcias, repetem a bisavó, obrigada a se casar com um homem, amando outro, fato que pontua um dado "trágico" a atingir o desejo, aparentemente, banido e substituído pelo grotesco perfil das viúvas. Dorotéia volta impelida pela culpa, após a morte do filho. O médico, chamado para salvá-lo, rejeita seu dinheiro, trocando-o por relações sexuais com ela. O corpo de um no lugar de outro e, no intervalo, a perda, jamais esquecida pela jovem mãe, que se recusa, morbidamente, a enterrar o menino até ser denunciada por uma vizinha.

12 V. sobre as encenações o perspicaz depoimento de Sábato Magaldi, em seu Nelson Rodrigues: dramaturgia e encenações. São Paulo: Perspectiva, (Col. Estudos, 98), p. 99-100. 
Rev. ANPOLL, n. 6/7, p. 21-35, jan./dez. 1999

$\Lambda$ s viúvas demoram a arrancar o segredo da recém- chegada. Seu rosto nu dá lugar à dissimulação, a uma máscara diversa, na tentativa de se fazer passar por uma parente homônima e suicida. Especular, ela precisa "afogar" a história pessoal no mar... revivendo a morte da "outra" Dorotéia. E, em meio a questões inquisidoras de D. Flávia, afirma ter experimentado a náusea, garantindo ter sido tocada por um só homem: "...o senhor meu marido" - declaração fulcral a ser revivida nas passagens fundamentais do conto de Dalton, a saber, título e bilhete sarcástico de Maria, instante no qual tem voz e letra.

Em linhas gerais, prostituição, censura e resistência conduzem a peça de Nelson, composta por três atos e publicada em 1947. Mais amena que as demais do ciclo ${ }^{13}$, Dorotéia articula uma contaminação de formas teatrais oscilantes entre momentos de angústia e risos de alívio, acompanhando quadros geradores de tensão entre desejo, culpa e morte. O caricatural e as ações paródicas preservam certo sentimento trágico, pois a máscara do cômico não apaga a dor resultante do estigma que recai sobre o destino das personagens. $\Lambda$ s viúvas morrem, restando Dorotéia - coberta de chagas - e a prima dominadora a aguardarem o apodrecimento em vida.

Tematicamente, os três textos comportam resquícios do universo patriarcal em que o "marido"/provedor tem direitos sobre o corpo feminino. $\Lambda$ "oposição" de cada uma se esboça de maneira peculiar. $\Lambda$ ssassinada, Maria Elvira é resgatada pelo "organdi azul" do vestido, lírica metáfora da incontestável liberdade do ser num universo segundo o qual o trágico, embora apequenado, subsiste.

Por sua vez, as duas "mulheres" de Dorotéia entregam-se às exigências de ordem moral e a morte lhes vem sub-reptícia, lenta e absoluta. Ora, ironicamente, a jovem-protagonista distanciara-se das parentes, contrapondo-se a leis repressivas, para viver demanda amorosa, prazeres e

13 Tal ciclo é formado por ílbum de família, Anjo Negro e Senhora dos Afogados, peças "de-sagradáveis" (segundo o próprio Nelson Rodrigues), posteriormente, rebatizadas por Sábato Magaldi, no prefácio "A peça que a vida prega", como "míticas". V. RODRIGUES, Nelson. Teatro Completo de Nelson Rodrigues. Rio de Janeiro: Nova Aguilar, 1993. 
PASSOS, Cleusa Rios Pinheiro. "Tragédias brasileiras": o diálogo de Dalton Trevisan...

maternidade, propiciando ao leitor a impressão de que escapara às normas familiares. No entanto, ela regressa, abdicando de beleza e sexualidade em nome da culpa, aceitando marcas no corpo graças à repetição do cotidiano, signo da recusa à rememoração e à mudança do núcleo.

A moça não reelabora as situações opressoras e inexplicáveis, há muito instituídas. Sua volta é um ato repetitivo, velado, um nó preso a algo faltante, aparentemente reproduzido pelo contato transferencial com o grupo, ligado a suas origens. O retorno ao mesmo ponto, ao lugar de onde partira, trará angústia e morte, embora as primas Maura e Carmelita quebrem regras, encontrando forças para rechaçar a tirania vigente por meio de delíros visuais e discursivos - exatamente o interdito, responsável pelo desaparecimento de ambas.

Abandonando o silêncio e os "ditos" estereotipados do verbo alheio em nome do desejo e da fala pessoal, após a "escuta" da experiência de Dorotéia, elas reagem e são assassinadas por Flávia. Se a contestação não comporta o traço lírico de Maria Elvira, insinua que as inversões podem não superar o destino, porém subvertem a ordem, tecendo uma rede, cujo centro espelha tanto o desejo irrealizável, quanto sua indestrutibilidade.

Conforme se vê, Trevisan reúne a poética condensação de Bandeira, no trabalho metonímico de substituição bairros-"namorados", e a volta de Dorotéia ao ambiente corrosivo de origem. Tais índices de persistente retorno assinalam algo singular em seu modo de compor: a repetição. Do poeta, seleciona o ato mencionado a fim de transformá-lo nas profissões e características sem nenhum relevo dos rivais, chegando à carência de individualidade já insinuada nos versos em questão: todos os amantes são um!

Do teatrólogo, parece recuperar na ação repetitiva o desenlace de suas personagens, a morte implacável e cruel de um cotidiano circular em que o prazer dá lugar à angústia e à inquietude diante de normas comportamentais, responsáveis pela proibição do toque e visão do corpo masculino. Apenas o olhar do marido é permitido: para o homem a pos- 
Rev. ANPOLL, n. 6/7, p. 21-35, jan./dez. 1999

sibilidade do prazer, para as mulheres a tragédia familiar da náusea, da "cegueira", da interdição onírica, da fala...

Logo, o diálogo com o poema e a peça mantém a negação do direito feminino ao uso do próprio corpo e à expressão do desejo como implacável denúncia, no entanto instaura diferenças. Se, à semelhança de Dorotéia, a personagem Maria tenta escapar ao ciclo fechado, impositivo e institucional, à procura do próprio desejo, acaba por regressar, não pela culpa que move a primeira, mas pela impossibilidade de sobrevivência sem seu "provedor". É ela quem introduz a ambivalência quanto a tais elos, deixando, ao fugir com o amante, um bilhete sarcástico preso ao espelho da penteadeira com goma de mascar:

"Sendo o senhor meu marido um manso sem vergonha, logo venho buscar as meninas/.../ só desprezo o que sinto, para mim o senhor não é nada".

Bem ao sabor de Dalton, $O$ senhor meu marido sai do contexto rodrigueano de logro e ocultamento para adentrar um "novo" e ambíguo espaço, reforçando o engodo das relações afetivas, mas o desmascarando cruamente. Nlém disso, o "companheiro" ganha o adjetivo evitado por Bandeira e proibido na linguagem das viúvas: "manso", vocábulo sugestivo da associação popular imediata - "corno".

Portanto, se Bandeira e Nelson são "predecessores" primorosos, Trevisan não os incorpora passivamente, imprimindo sua marca ao tema trabalhado pelos três, inclusive no ato de reduzir ressonâncias da tragédia. De extremo relevo, configuram-se as gradações do trágico ${ }^{14}$, básicas ao poema, peça e conto, não apenas pelo dialogismo, mas também por inserirem na ciranda textual brasileira a memória de literaturas alheias.

Diferentemente da tradicional (grega, latina, francesa etc.), estas são "tragédias" brasileiras, desprovidas de heróis de "reputação ou fortu-

14 Interessa-nos aqui a questão do "trágico" em suas acepções de substantivo/adjetivo, conforme sugere Anatol Rosenfeld na introdução de seu: O teatro épico. S. Paulo, 1965, col. Buriti, p. 1-26. 
PASSOS, Cleusa Rios Pinheiro. "Tragédias brasileiras": o diálogo de Dalton Trevisan...

na/.../ ou representantes de famílias ilustres" 15 , bem como sem a "imitação" de ações "de caráter elevado" 16 , conforme descreve Aristóteles. Todavia, parodicamente aclimatadas, comportam algo concernente a essa forma clássica, a saber, as circunstâncias, o condicionamento a um destino cego, o "terror e piedade", igualmente minimizados, diante do infortúnio que resulta em assassinatos abruptos ou graduais - os mais perversos? recobrando vínculos com desejo, transgressão e fatalidade.

"Flagelos" sociais, as figuras de Bandeira são revisitadas pela contística do escritor curitibano, que se vale da repetição para substituir o lírico do "organdi azul" e a morte brusca de Maria Elvira, reduzindo ainda mais o trágico do poema. Embora conceda à voz narrativa a suspensão do texto, não descarta as sugestões das contínuas mudanças de Maria e João, afinal, "sem conta são os bairros de Curitiba/.../". Vítimas de um terrível fardo, o par se sustenta na metáfora "gozoza" do processo afetivo, gerador de outra espécie de morte, paulatina e incessante.

E aí, especificamente, não é difícil aproximá-lo de Dorotéia e D. Flávia, pois ambas renunciam ao prazer e ao amor, submissas a uma indefinida agonia. O trabalho plástico da "mise en scène" encerraria, igualmente, a imaginativa conjunção entre relances surrealistas e aspectos da mitologia. Em certas passagens, as viúvas relembram as Moiras, ora por punições aos trangressores das leis (D. Flávia), ora pela sorte implacável de cada personagem.

Aliás, recuperando versões diferentes, o dramaturgo subverte a mitologia que transformara a "moira", após as epopéias homéricas, em três irmãs. No caso de Dorotéia, as primas se condensam em uma, recebendo os atributos das demais e integrando "ipseidade e alteridade" - mais um recurso de encaixe e articulação dos elos dialógicos de uma cadeia longa e inusitada. Sintomaticamente, a peça inserida na rede intertextual aqui ras-

15 ARISTÓTELES. Pó́tica. Eudoro de Sousa (trad.). Porto Alegre: Globo, 1966, p. 69.

16 IDEM. lbidem, p. 37. 
treada se vale de outros fios, reelaborando "antigas" tradições helênicas. Nliada ao riso como exposição da hipocrisia e preconceitos sociais, ao apequenando das "figuras" do destino e revelando parte dos temas e procedimentos das cenas, a rede absorve e reedita situações peculiares, numa paródica permuta com traços do Surrealismo (à guisa de exemplo, objetos em aparência desconexos, como "botas" e "jarro", tomam o lugar cênico de corpo e desejo).

$\Lambda$ ssim, talvez, para além do esperado pelo próprio Dalton, a leitura de "O senhor meu marido" não apenas estabelece laços com contextos literários distintos, também fundados em refaturas e inversões do "conhecido", mas ilustra um caminho que, ao assimilar trechos de uma obra diversa, suscita um encadeamento imprevisível. Sempre em busca de relações recorrentes, nas quais o jogo vampiresco escapa à mera transfiguração do "outro" no "mesmo", o autor acaba por insinuar um dialogismo sutil - oposto a passagens "explícitas" ou debochadas de seus escritos - responsável pelo aflorar de diferenças e ligações culturais vastas.

No caso presente, o "resgate" de ecos da tragédia se vai diluindo, sem que a perda implique seu esquecimento em nosso fazer literário, historicamente pouco vinculado a ela. Cabe lembrar que o teatro brasileiro de alguma envergadura manifesta-se, sobretudo, no período romântico, não tendo passado, portanto, pela fase neoclássica, na qual tal forma era considerada um dos grandes "modelos" de composição artística.

No Brasil, adentra primacialmente como espetáculo - resultado do esforço de companhias - e dado cultural relevante, não se podendo falar em tradição trágica. Nos três autores, aflora na condição de portadora de ecos matizados, constituindo, por outro lado, um liame expressivo a incorporar experiências em dramaturgia, prosa e verso, graças a um denominador comum: as ressonâncias paródicas que sustentam discreta presença de estéticas estrangeiras, ao lado de significativo diálogo entre nossas próprias criações. 
PASSOS, Cleusa Rios Pinheiro. "Tragédias brasileiras": o diálogo de Dalton Trevisan...

Logo, do ângulo da literatura brasileira, esboça-se uma relação de continuidade que, aclimatando e desenvolvendo elementos provindos da produção trágica ocidental, sabe estabelecer correspondências entre os textos aqui selecionados, nos quais uma de suas marcas significativas está em rearranjar o alheio - nacional e estrangeiro - respeitando o tom e a pespectiva de cada trabalho inventivo, conservando o que Alencar, em termos aproximados, já percebera no tocante a seu romance Senhora ${ }^{17}$ : talha-se "o tamanho" da ficção de acordo com tom e contexto.

Retomar esse ponto nunca é demais, quando se trata do intertexto e suas inúmeras funções em determinados autores. Especificamente, tal procedimento teórico começa por conferir um dos sentidos às repetições importantes de Dalton no conjunto de seus livros, aumenta o espectro literário da narrativa enfocada e, sobretudo, ancora um traço básico de sua fatura: preenche o vazio resultante da ausência de entendimento verbal/ afetivo entre seus protagonistas. À falta de diálogo entre o casal, impõe-se o sub-reptício diálogo com obras voltadas para preocupações semelhantes, embora diferentemente tratadas.

De modo amplo, o trabalho intertextual pontua contornos insistentes na circulação de temas e formas, contribuindo para que a elaboração estética e sua leitura se perfaçam não mais como algo fechado em si mesmo e, sim, como entrecruzamento, só possível pelo fato de que sistemas e subsistemas literários instituem vinculações abertas, historicamente delineadas e recriadoras do perene e necessário diálogo entre as obras.

17 ALENCAR, J. Senhora. 3a. (s.l.), Edições Melhoramentos, (s.d.), p. 342. 
Rev. $A N P(O L L$, n. 6/7, p. 21-35, jan./dez. 1999

RÉSUMÉ: Le conte "O senhor meu marido" de Dalton Trevisan récupère intertextuellement des éléments issus d'un poème de Manuel Bandeira ('Tragédia Brasileira') et d'une pièce de Nelson Rodrigues (Dorotéia). Il s'agit d'un réseau dialogique qui relève des thèmes concernant le désir, la censure et l'assujettissement de la femme et qui propose, d'autre part, le processus intertextuel au sein même de la littérature brésilienne, considérée comme un champ possible d'exploration.

MOTS-CLÉS: intertextualité; Dalton Trevisan; littérature brésilienne. 